\title{
Combining Sectioning Method and X-Ray Diffraction for Evaluation of Residual Stresses in Welded High Strength Steel Components
}

\author{
Arne Kromm ${ }^{1, a^{*}}$, Michael Rhode ${ }^{1, b}$, Benjamin Launert ${ }^{2, c}$, Jonny Dixneit ${ }^{1, d}$, \\ Thomas Kannengiesser ${ }^{1, \mathrm{e}}$ and Hartmut Pasternak ${ }^{2, \mathrm{f}}$ \\ ${ }^{1}$ Bundesanstalt für Materialforschung und -prüfung (BAM), Unter den Eichen 87, 12205 Berlin, \\ Germany \\ ${ }^{2}$ Chair of Steel and Timber Structures, Brandenburg University of Technology (BTU), \\ Konrad-Wachsmann-Allee 2, 03046 Cottbus, Germany \\ aarne.kromm@bam.de, bmichael.rhode@bam.de, cbenjamin.launert@b-tu.de, \\ djonny.dixneit@bam.de, ${ }^{e}$ thomas.kannengiesser@bam.de, ${ }^{f}$ hartmut.pasternak@b-tu.de
}

\section{Keywords: Weld Residual Stress, Sectioning Method, X-Ray Diffraction}

\begin{abstract}
Residual stresses and distortions in welded I-girders for steel construction are relevant when evaluating the stability of steel beams and column members. The application of high strength steels allows smaller wall thicknesses compared to conventional steels. Therefore, the risk of buckling has to be considered carefully. Due to the lack of knowledge concerning the residual stresses present after welding in high strength steel components conservative assumptions of their level and distribution is typically applied. In this study I-girders made of steels showing strengths of $355 \mathrm{MPa}$ and $690 \mathrm{MPa}$ were welded with varying heat input. Due to the dimension of the I-girders and the complex geometry the accessibility for residual stress measurement using X-ray diffraction was limited. Therefore, saw cutting accompanied by strain gauge measurement has been used to produce smaller sections appropriate to apply X-ray diffraction. The stress relaxation measured by strain gauges has been added to residual stresses determined by X-ray diffraction to obtain the original stress level and distribution before sectioning. The combination of both techniques can produce robust residual stress values. From practical point of view afford for strain gauge application can be limited to a number of measuring positions solely to record the global amount of stress relaxation. X-ray diffraction can be applied after sectioning to determine the residual stresses with sufficient spatial resolution.
\end{abstract}

\section{Introduction}

This work is part of an ongoing research project on recommendations for the implementation of welding imperfections in the numerical analysis of welded thick-walled I-girders. One focus is put on welding residual stresses and their impact on the stability of specific components. Simulation approaches for capacity design are often quite conservative due to lack of knowledge concerning important input parameters [1]. For example, welding residual stresses are often assumed to be tensile up to the yield strength in the heat affected zone (HAZ). This is not the case especially when welding high strength steels which show a stress reducing effect due to solid state phase transformations [2-3]. The resulting extent of equilibrium compressive residual stresses is important for the ultimate load. But experimental proofs of spatially resolved residual stresses for welded thickwalled I-girders are difficult to obtain due the limited accessibility of such structures. Especially the HAZ adjacent to the weld restricts local measurements as it is covered by the parallel chords even in large scale I-girders. The sectioning method is an established technique to determine residual stresses in larger structures. Strain gauges are applied on the surface of the specimen. Sectioning by saw cutting leads to stress/strain relaxations which are recorded by strain gauges locally. Applying a large 
number of strain gauges the stress relaxation can be calculated accurately. The spatial resolution is in principle limited by the geometry of the strain gauge. In the present work the sectioning method was combined with residual stress determination by X-ray diffraction (XRD). For this purpose the I-girders were cut just to the size until the areas of interest were accessible by XRD. The final residual stresses were determined by simply summing up the stresses found by sectioning and subsequent XRD.

\section{Experimental}

Welding. Full-scale specimens welded at a steelwork company were used. The high strength steels S355J2+N and S690QL (minimum yield strength: $355 \mathrm{MPa}$, respectively $690 \mathrm{MPa}$ ) were welded by gas metal arc welding (GMAW). The plate thicknesses were $20 \mathrm{~mm}$ for the chords and $10 \mathrm{~mm}$ for the web plate. Fillet welding was performed using strength matching filler materials in a single layer. Important parameters are shown in Table 1. Two heat inputs were applied varied mainly by the welding speed.

Table 1: Welding parameters

\begin{tabular}{|l|l|l|l|l|l|}
\hline Sample & Material & $\begin{array}{l}\text { Current } \\
{[\mathrm{A}]}\end{array}$ & $\begin{array}{l}\text { Voltage } \\
{[\mathrm{V}]}\end{array}$ & $\begin{array}{l}\text { Welding speed } \\
{[\mathrm{cm} / \mathrm{min}]}\end{array}$ & $\begin{array}{l}\text { Heat input } \\
{[\mathrm{kJ} / \mathrm{cm}]}\end{array}$ \\
\hline 355L & \multirow{2}{*}{ S355J2+N } & 328 & 33 & 64 & $10.1($ low $)$ \\
\cline { 3 - 6 } & & 329 & 33 & 40 & 16.3 (high) \\
\hline $355 \mathrm{H}$ & \multirow{2}{*}{ S690QL } & 343 & 33 & 64 & 10.6 (low) \\
\cline { 3 - 6 } & & 338 & 33 & 40 & 16.7 (high) \\
\hline 6
\end{tabular}

Sectioning. Sectioning was performed using a conventional band saw. The sections are indicated in Fig. 1. The cutting strategy was chosen from preliminary tests taking into account the strain gauge response and also literature recommendations [4]. The strains were recorded longitudinally and transversely to the welding direction. From these strains the stresses in longitudinal direction were calculated.
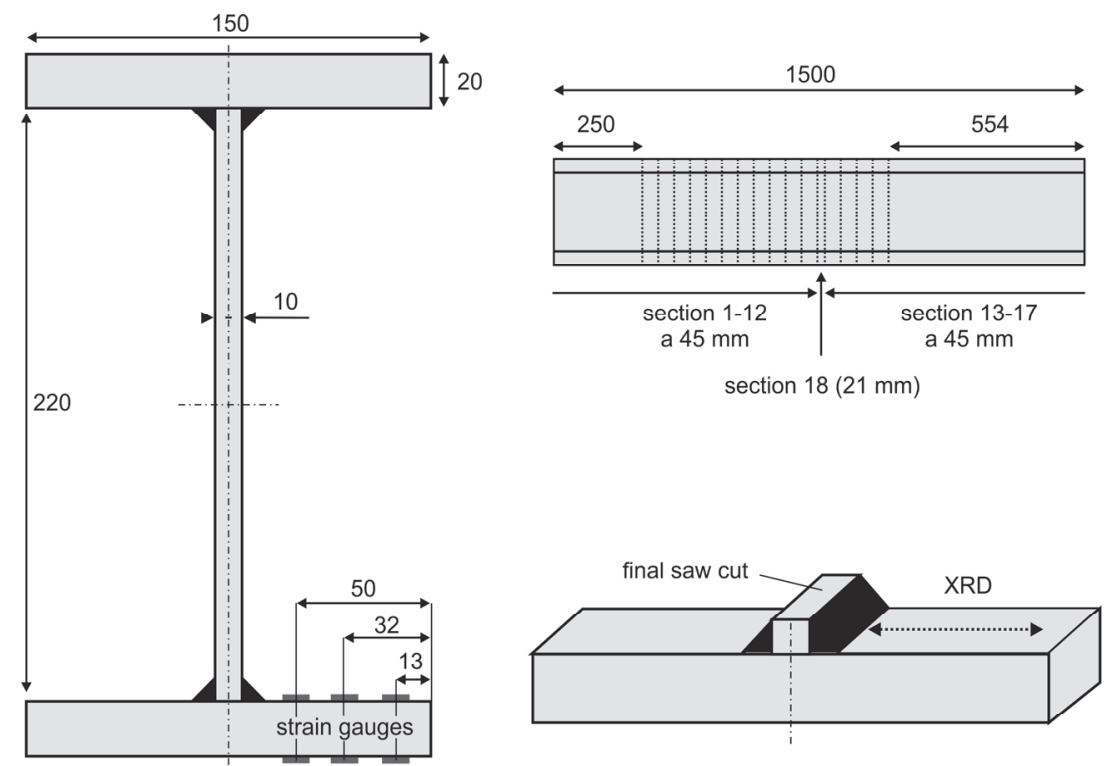

Figure 1: Schematic of sectioning, position of the strain gauges and measuring position for XRD 
The first section had a length of $250 \mathrm{~mm}$. From cut number two on the sections had lengths of $45 \mathrm{~mm}$. Cut number twelve was located directly adjacent to the strain gauges. The second half of the beam was then cut beginning from the other side. Section number 13 had a length of $554 \mathrm{~mm}$. Sections 14 to 17 showed again lengths of $45 \mathrm{~mm}$. The resulting section number 18 which carried the strain gauges then resulted in a length of $21 \mathrm{~mm}$. From this last section the chords were cut from the fillet and used for final residual stress measurement by XRD as shown in Fig 1.

X-ray diffraction. The residual stresses in longitudinal direction were determined using the $\sin ^{2} \psi$-method. Measuring and evaluation parameters are given in Table 2. The measurements were performed along a line starting adjacent to the weld covering the HAZ and the base material. Up to 19 points were chosen along a distance of $50 \mathrm{~mm}$ (see Fig 1). The measurement was made at the welded side and also at back side of the chords at similar positions.

Table 2: Measuring and evaluation parameters for residual stress analysis by XRD

\begin{tabular}{|l|l|}
\hline Focus & $2 \mathrm{~mm}$ \\
\hline Radiation & CrK $\alpha$ \\
\hline Diffraction line & Ferrite: 211 \\
\hline $\mathrm{E}\{211\}$ and $v\{211\}$ & $220.000 \mathrm{MPa}$ and 0.28 \\
\hline
\end{tabular}

\section{Results and Discussion}

Longitudinal residual stresses determined from the strain gauge response at the upper (weld) and lower side of the chords are shown in Fig. 2 and Fig. 3. The closer the strain gauge was located relative to the weld the higher the stresses were. Up to $100 \mathrm{MPa}$ were found adjacent to the weld independent from the material or the heat input. Away from the weld the stresses turned into compression. The mid and the outer position showed about -50 MPa. The back side of the chords was characterized by quite constant compressive residual stresses between approximately $-50 \mathrm{MPa}$ to $-100 \mathrm{MPa}$. With higher heat input (Fig. 2, right and Fig. 3, right) the stresses tended to show slightly higher absolute values. In the following the stresses obtained at three fixed positons by strain gauges were added to the spatially resolved stresses obtained from XRD. Ranges were defined for each strain gauge - indicated in Fig. 2 and Fig. 3 by the dashed lines - in which the stresses from the strain gauges were assumed to be constant.
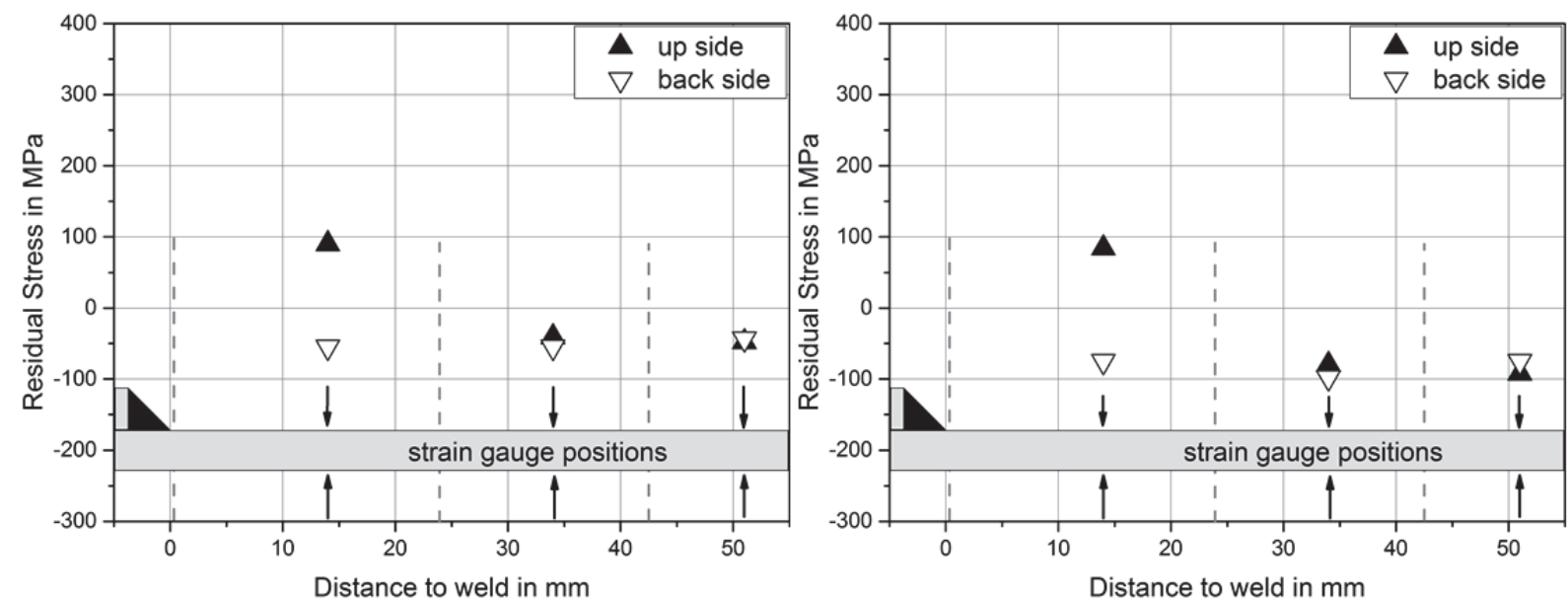

Figure 2: Longitudinal residual stresses determined by strain gauges during sectioning of samples $355 \mathrm{~L}$ (left) and $355 \mathrm{H}$ (right) 

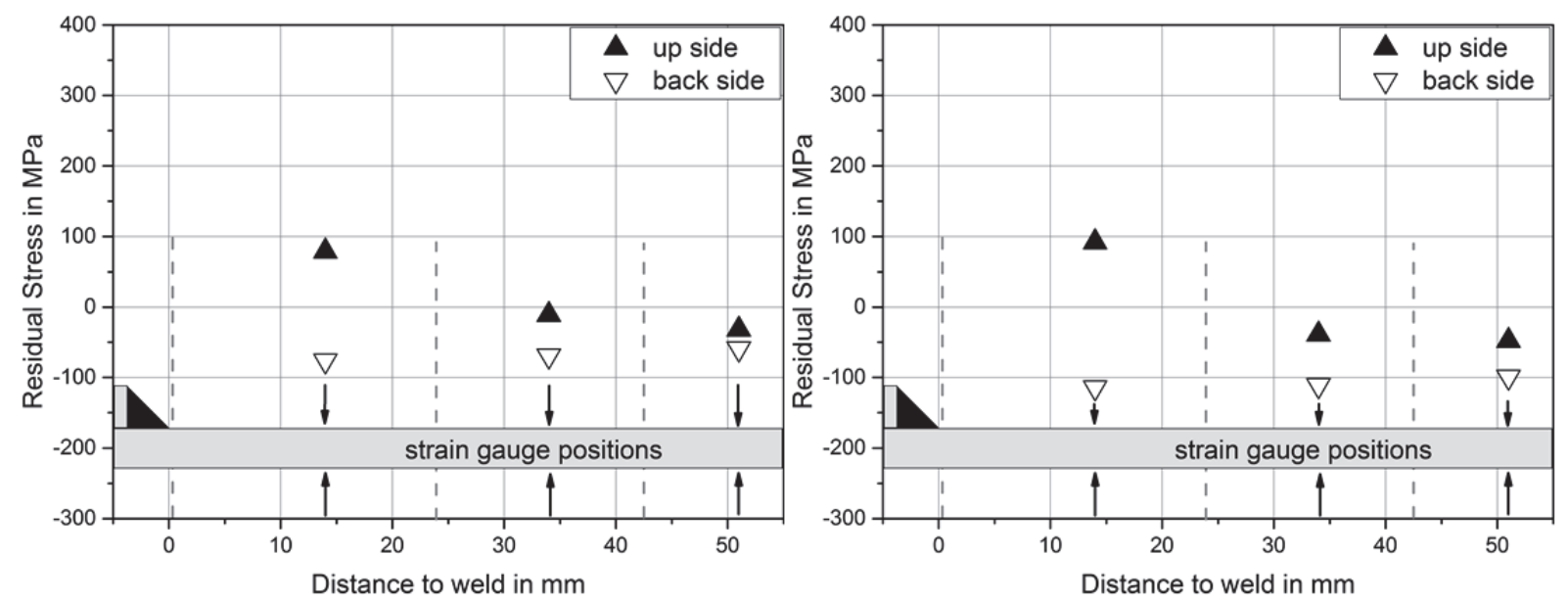

Figure 3: Longitudinal residual stresses determined by strain gauges during sectioning of samples $690 \mathrm{~L}$ (left) and $690 \mathrm{H}$ (right)

Residual stresses determined from XRD after sectioning are shown for S355 in Fig. 4. The highest stresses were found close to the weld at the upper side of the chord. For the low heat input up to $300 \mathrm{MPa}$ were registered. At high heat input up to $200 \mathrm{MPa}$ remained after sectioning adjacent to the weld. Within the first $10 \mathrm{~mm}$ a gradient was present in the HAZ. Here the stresses turned into compression. Approximately -100 MPa were left in the base material. The back side of the chords showed stresses near $0 \mathrm{MPa}$ in the range near the weld. The rest was characterized by stresses between $0 \mathrm{MPa}$ and $-100 \mathrm{MPa}$, which may stem from initial fabrication stresses present in the plates before welding. Note, that the plates were not subjected to stress relieve heat treatment prior to welding. No cutting influence is expected due to waterjet-cutting of the plates. The XRD results are always affected by the surface preparation which was critical at some points. This applied also in quality to the high strength steel S690 shown Fig. 5. The chord back side showed the same stress distribution also in quantity. Differences to S355 appeared at the upper side of the chord. Adjacent to the weld metal the tensile stress showed a dip. The stress was decreased here between $50 \mathrm{MPa}$ and $150 \mathrm{MPa}$ dependent on the heat input. Low heat input formed lower stresses at all. In the base material the stresses were around $0 \mathrm{MPa}$.
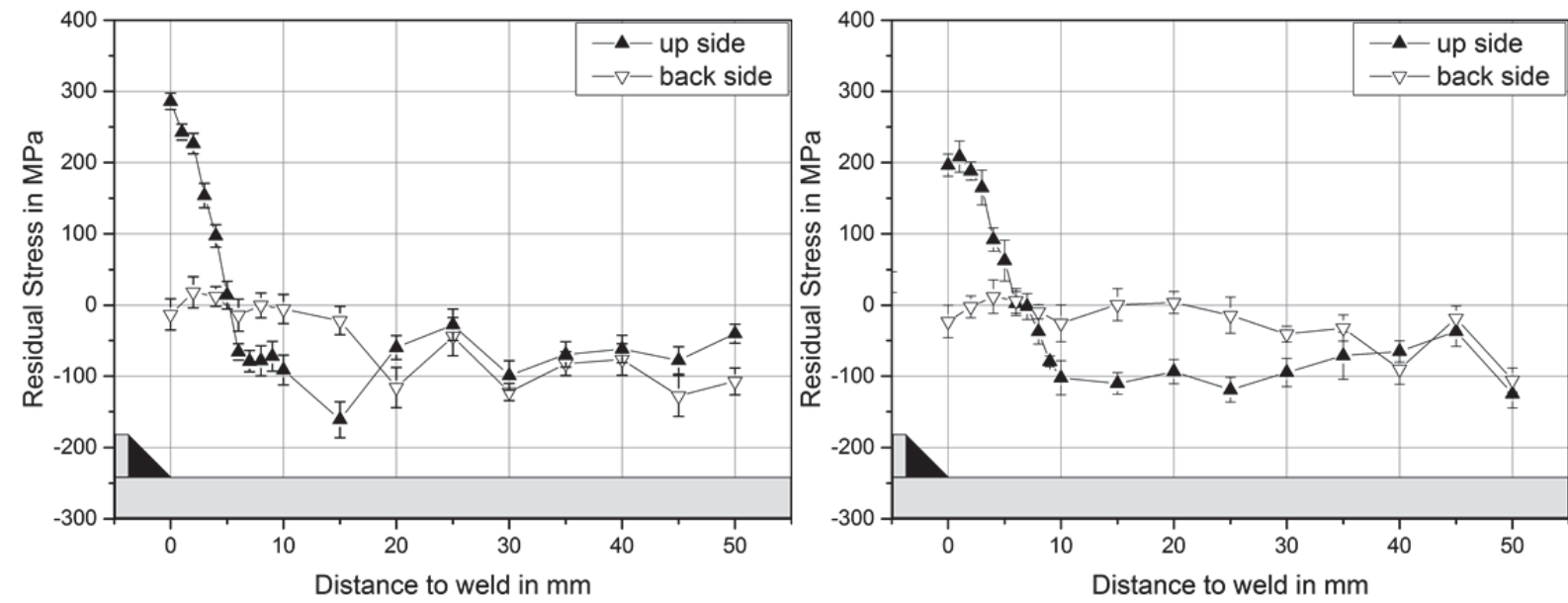

Figure 4: Longitudinal residual stresses determined by XRD after sectioning of samples $355 L$ (left) and $355 \mathrm{H}$ (right) 

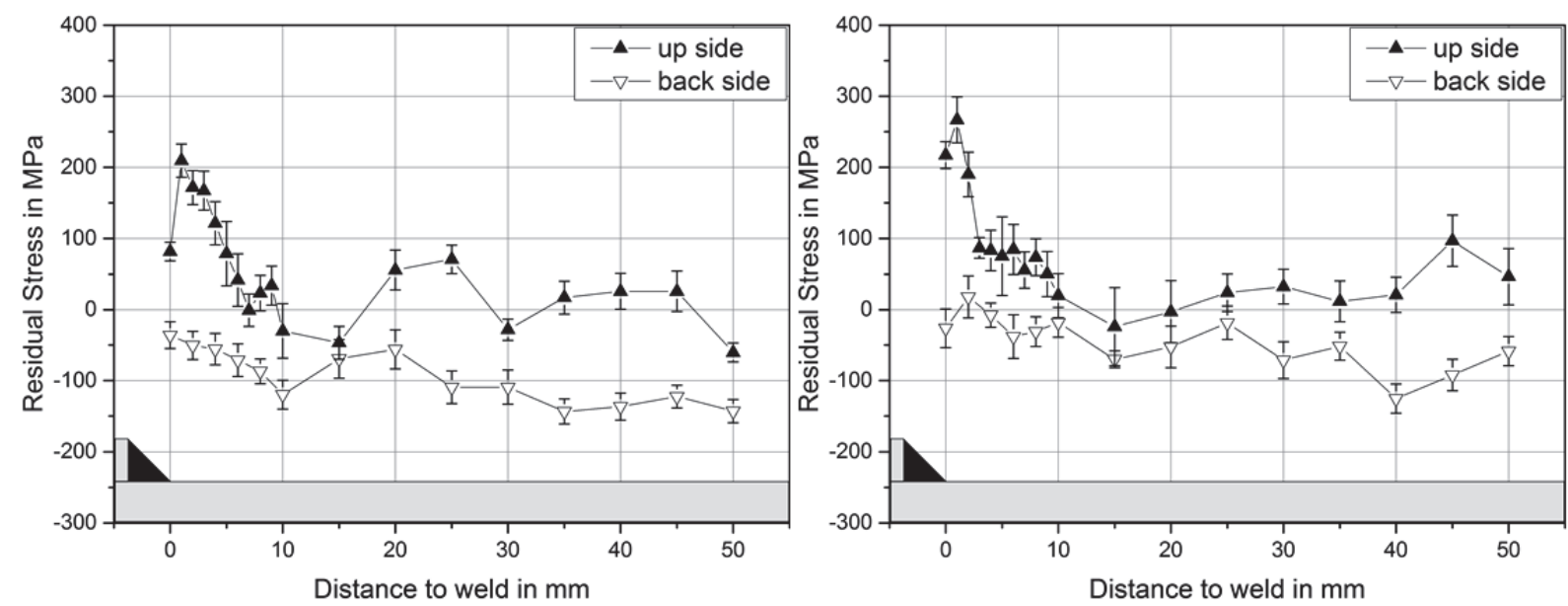

Figure 5: Longitudinal residual stresses determined by XRD after sectioning of samples $690 \mathrm{~L}$ (left) and $690 \mathrm{H}$ (right)

After superposition of the stresses from sectioning and XRD the differences between HAZ and base material became higher. The highest tensile stresses up the yield strength were obtained for S355 welded with low heat input adjacent to the weld (see Fig. 6). The stresses remained tensile within a distance of $10 \mathrm{~mm}$ to the weld. With higher distance to the HAZ the stresses changed into compression up to $-200 \mathrm{MPa}$. The stresses at the back side are in principle in compression showing the same absolute values as on the upper side. Also the back side of S690 was completely in compression up to $-200 \mathrm{MPa}$ (see Fig. 7). The upper side showed around $0 \mathrm{MPa}$ far from the weld and HAZ. In the HAZ the highest tensile stresses were found around $2 \mathrm{~mm}$ away from the weld metal. In the transition to the weld the stresses were decreased from $300 \mathrm{MPa}$ to about $150 \mathrm{MPa}$ at low heat input. For the high heat input this decrease was less, from $360 \mathrm{MPa}$ to $310 \mathrm{MPa}$. Related to the yield strength of the materials the higher stresses, up to the yield point, were present in the mild steel S355. The high strength steel S690 was stressed just to $52 \%$ of the yield strength. As the geometry (restraint) of the samples was similar in each case the main reason was assumed to be the phase transformation behavior. Stress release by martensite formation is known to be effective in high strength steels [2-3].
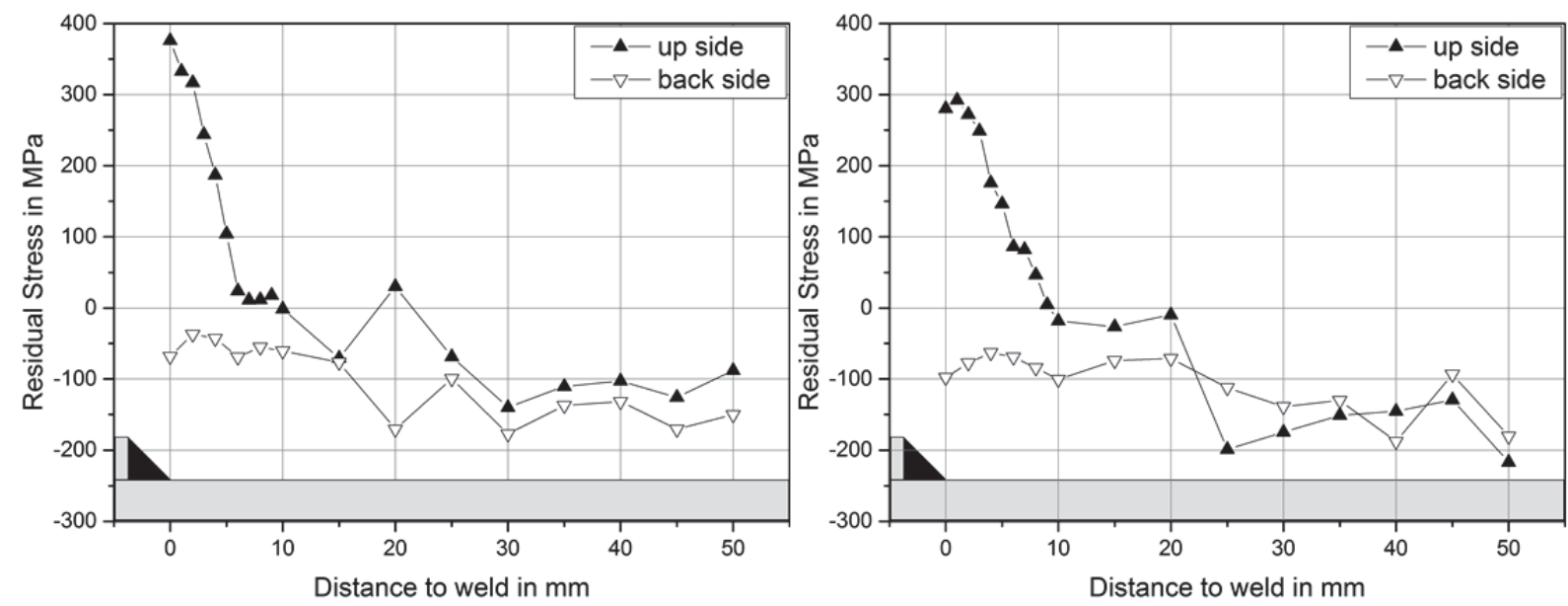

Figure 6: Longitudinal residual stresses determined from strain gauges and XRD of samples $355 \mathrm{~L}$ (left) and $355 \mathrm{H}$ (right) 

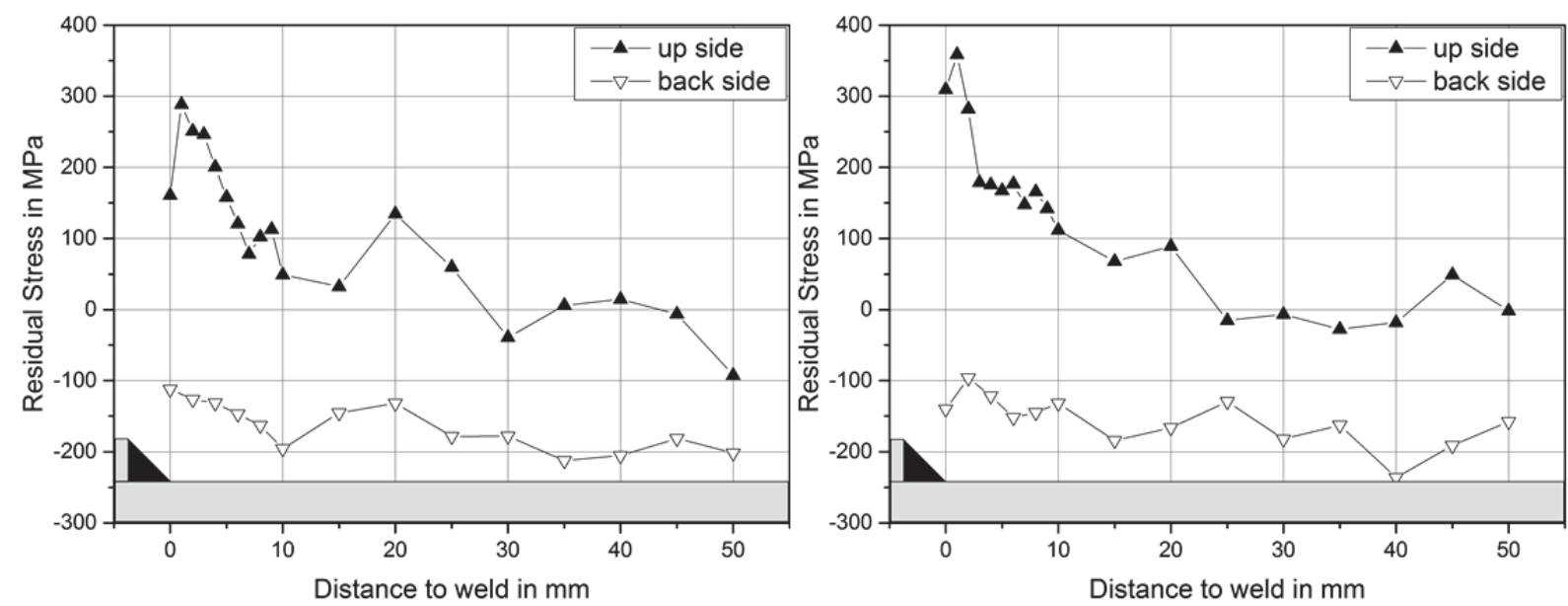

Figure 7: Longitudinal residual stresses determined from strain gauges and XRD of samples 690L (left) and 690H (right)

\section{Summary}

Residual stresses were determined on welded I-girders made of S355 mild and S690 high strength steel. A combination of the sectioning method and XRD was applied. The residual stresses released during sectioning showed a similar level independent from the material and the heat input applied. XRD has shown that the local residual stresses present in the HAZ are less affected by the heat input but were characteristic for the type of steel welded due to the impact of the solid state phase transformation. Residual stresses in the mild steel S355 reached the yield point, while the stresses in the high strength steel S690 just showed about half of that. Extensive use of strain gauges is just necessary to record the global stress relaxation by sectioning in order to have sufficient access by XRD. The latter can be applied then to ensure residual stress determination with high spatial resolution.

\section{Acknowledgements}

This IGF-project (IGF-project-no. 18104 BG) of the Research Association for Steel Application (FOSTA) was supported by the Federal Ministry for Economic Affairs and Energy by the AiF as part of the program for support of the cooperative industrial research (IGF) on the basis of a decision by the German Bundestag. Sincere thanks are given for this support and to the representing companies actively involved in the project board.

\section{References}

[1] H. Pasternak, B. Launert, T. Krausche, Welding of Girders with Thick Plates - Fabrication, measurement and simulation, Journal of Constructional Steel Research 115 (2015) 407-416. http://dx.doi.org/10.1016/j.jcsr.2015.08.037

[2] T. Nitschke-Pagel, H. Wohlfahrt, Residual Stresses in Welded Joints - Sources and Consequences, Mater. $\quad$ Sci. $\quad$ Forum $\quad 404-407 \quad$ (2002) 215-226. http://dx.doi.org/10.4028/www.scientific.net/MSF.404-407.215

[3] J. Hensel, T. Nitschke-Pagel, K. Dilger, S. Schönborn, Effects of Residual Stresses on the Fatigue Performance of Welded Steels with Longitudinal Stiffeners, Materials Science Forum 768-769 (2014) 636-643. http://dx.doi.org/10.4028/www.scientific.net/MSF.768-769.636

[4] N. Tebedge, G. Alpsten, L. Tall: Residual-stress Measurement by the Sectioning Method, Experimental Mechanics, 13 (1973) 88-96. http://dx.doi.org/10.1007/BF02322389 